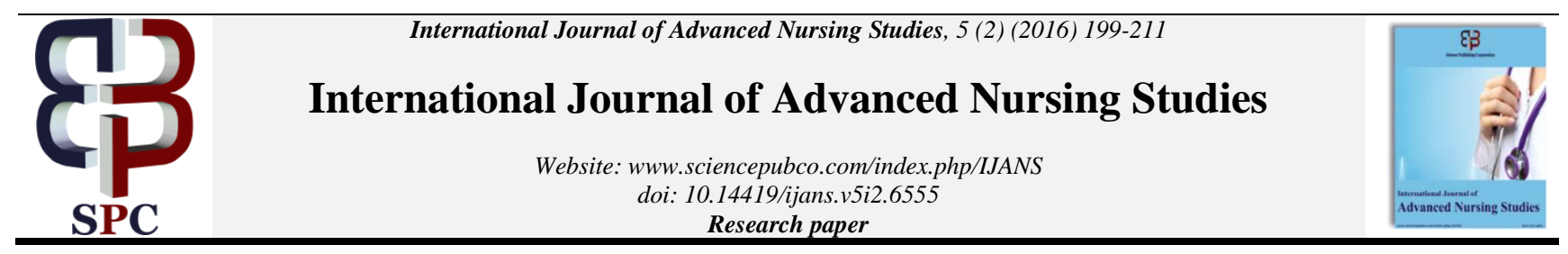

\title{
Conceptualisation as basis for the development ofcritical thinking within the nursing perspective
}

\author{
Louise Pretoruis ${ }^{1 *}$, Agenus Van Dyk ${ }^{2}$, Luis F Small ${ }^{1}$, Hans Justus Amukugo ${ }^{1}$ \\ ${ }^{1}$ Lecturers, School of Nursing and, Faculty of health Sciences University of Namibia \\ ${ }^{2}$ Full Professor and Dean School of Nursing Lecturer, International University of Management \\ *Corresponding author E-mail: lpretorius@unam.na
}

\begin{abstract}
The purpose of this article is to present the conceptualise empirical findings arrived at from the needs assessment (phase 1), which reflected the application of critical thinking skills by the respondents. The ultimate aim was to develop an educational programme to facilitate critical thinking in nursing practice. Conceptualization as the definition of key concepts in a study with a view to integrating one's research into conceptual frameworks.

The findings revealed six main concepts and their related sub-concepts. These concepts included interpretation, analysis, evaluation, inference, explanation and self-regulation. These concepts were inferred from the deduction by the researcher. These concepts were the results of the concept analysis of critical thinking by 46 experts directed by Facione together with the related dispositions. These six main concepts constituted the framework within which the educational programme was developed. The following steps were followed during the conceptualization namely concepts synthesis, clarification of the concepts, interpretation of the concepts, analysis of the concepts, evaluation of the concepts, interference/ conclusion, explanation, self - regulation and critical approaches.
\end{abstract}

Keywords: Conceptualisation; Development, Critical Thinking Nursing Perspective.

\section{Introduction}

Conceptualization as the definition of key concepts in a study with a view to integrating one's research into conceptual frameworks Mouton (1998. The term also refers to a category of perceptions or experiences (De Vos, 2002(b)). It is accepted that everyone thinks since it is our nature to do so. Thinking is a dynamic, every day, non-static process which may change daily or hourly and which may have a major impact on one's life. For daily activities one relies on different modes of thinking. One may rely on past experience or may decide to approach a case in a new way. It is important to realize that just about everything one does requires thinking, although not all thinking is the same (Rubenfeld \& Scheffer, 1999). Rubenfeld and Scheffer (1999) are of the opinion that the better one understands thinking, the easier it is to develop and nurture one's thinking, especially when it comes to situations that demand more than superficial thinking.

Thinking is a primary skill for all scientific disciplines and professions, including nursing. Thinking makes it possible for the nurse to execute nursing activities for the benefit of her/his client (Lindberg, Hunter \& Kruszewski, 1998, p. 4; Rubenfeld \& Scheffer, 1999, p.5). However, for the nurse it is necessary to realize that a higher level of thinking than that required by daily activities is required to solve nursing problems, because solving these problems involves the processing of complex data and the making of intelligent decisions concerning the planning, management and evaluation of health care (Shin, 1998,).

One can then ask what the difference between thinking and critical thinking is. The difference lies in "purpose" and "control". Thinking can be mindless and mere daydreaming, whereas critical thinking is purposeful and controlled and focuses on well-reasoned strategies directed towards a specific outcome (Alfaro-LeFevre, 2004). It is a range of abilities and qualities that inform direct and control our thinking and actions (Brown \& Rutter, 2004).

The concept of critical thinking has been defined by different people over the years and yet it has never been possible to produce a single definition. The expression "critical thinking" has become so popular that people who are unable to agree on most of the important things in life are likely to claim that they think critically (Carroll2007,). Critical thinking has been covered by a wide array of disciplines that cited specific reasons why critical thinking was important within their field, and still it is difficult to come up with a single definition for critical thinking. The ability to think critically has been identified by researchers, both past and present, as a skill that is reflective of higher order thinking (Thurmond, 2001; Hagerman, 2004).

It is, however, necessary to emphasize that critical thinking in day-to-day activities cannot be thought of as something that seeks out perfect solutions but rather as a process and mental orientation that includes cognitive and affective domains of reasoning. Critical thinking in daily activities is thinking with a purpose, and with skill and confidence. It is also about paying careful attention to what we hear and read so that we can understand and respond appropriately. As critical thinkers we are not striving to become unfeeling or emotionless people, but rather to make judgments in which our feelings and emotions are properly expressed (Jones, 2001; Simpson \& Courtney, 2002; Salmon, 2002,; Brown \& Rutter, 2004; Howard College, 2006).

Critical thinking means that we take nothing for granted, but rather ask questions so that we become informed about situations around us and are willing to examine conflicting positions in a fair-minded way and accept that even beliefs that we have held all our lives might be wrong! Once an individual has used the critical 
thinking process in one area of life or work, it is more likely that the same individual will apply the process in other domains (Robinson, 1998; Potter \& Perry, 1999,; Carroll, 2007).

Makathini (1992, p.24) has described an ability to think critically as an antecedent to problem solving. Furthermore, critical thinking is regarded as a practical activity that helps learners develop a broad understanding of situations that are meaningful to them (Mpaka \& Uys, 1999). Buchanan (n.d., p.1) describes the term "critical thinking" as intimidating, but concludes by saying that critical thinking, by definition, is "what you generate, is what you know".

During a quantitative study conducted by Facione (1990) 46 critical thinking experts participated in a Delphi study. Critical thinking was then conceptualized in terms of cognitive skills and affective dispositions. Consensus have been reached that critical thinking is purposeful, self-regulatory judgment which results in interpretation, analysis, evaluation and inference, explanation as well as self -regulation. The author also indicated that the critical thinker is habitually inquisitive, well-informed, trustful in reason, open0minded, flexible, fair minded in evaluation, honest in facing personal biases, prudent in making decisions and willing to reconsider. The critical thinker is also reasonable in selection of criteria keep focused on criteria and remain persistent in seeking results. Nurturing the developing of critical thinking encompasses the six core critical thinking concepts as well as the sub skills that serve as support to the main concepts (Facione 1990).

A clear and accurate conceptualization of these concepts is necessary for the development of effective instructional programmes. In this study, the six core critical thinking concepts and its sub skills have been conceptualized in. it also served as the foundation to the educational programme that was developed in phase 3 of the study. Though the panel strove to characterize certain core concepts, the experts did not claim that a person should be proficient in all the core concepts to be perceived as a critical thinker. The panel furthermore considered these concepts as essential to the design and implementation of critical thinking instruction (Facione, 1990). The consensus of core critical thinking concepts and its sub-skills as were reached by the experts of the Delphi study.

Critical thinking is considered one of the essential tools for coping with everyday life crises. As life progresses, nothing becomes simpler; in fact life only becomes more complicated and if we want to survive we must be able to think critically. It is argued that the ability to think critically is fundamental to the ability to function as a competent member of society. Critical thinking encompasses a number of skills, which means that the term is holistic in nature. "Holistic" refers to the idea that the whole of something needs to be understood in terms of its parts.

In addition, critical thinking involves the whole of a person, namely body and mind. To think critically there must be a certain amount of self- awareness and other characteristics present to enable the critical thinker to explain the processes of analysis and interpretation (Applegate, 1998; Cooke \& Moyle, 2002; Walker, 2003; Alfaro-LeFevre, 2004 (b), Hornby, 2005).

As members of society, people are involved in different professions and contexts where critical thinking skills can be exercised. Critical thinking is considered the style of thinking that is necessary for success with all other processes and an activity that will empower people to adhere to standards relating to a specific context. The value of critical thinking lies in its ability to result in better plans and actions in a specific context (Pond, Bradshaw \& Turner, 1991,; Alfaro-LeFevre, 2002; Lipe \& Beasley, 2004)

It became clear that the promotion of critical thinking is a key element in meaningful, responsible and soulful learning. By teaching people to make good decisions, one equip them to achieve a better future and become contributing members of society rather than burdens on society (Murchù \& Muirhead, 2005; Facione, 2006).

The facilitation and development of critical thinking in members of society is considered an educational ideal whereby students can be empowered to control their own destiny. It is also in line with the desire to not only develop individuals but to develop the nation (Finke, 1998; Bandman \& Bandman, 1988).

The context within which this study was conducted is the clinical nursing environment within a health care delivery system in Namibia. Concept synthesis is defined by Walker and Avant (2005) as a strategy to extract or pull together concept(s) from a body of data or set of observations. Furthermore, data for concept synthesis can be obtained from direct observation, quantitative evidence, literature, or a combination of the three (Walker \& Avant, 2005).

The development of a conceptual framework for the educational programme to facilitate critical thinking in student nurses was based on a synthesis strategy whereby central concepts were formed from empirical evidence obtained from phase 1 . The questions on the case scenario were formulated to address certain critical thinking skills that were found in the literature to be important in managing problem cases of this nature. The researcher decided on the strategy of a case scenario because much has been written on the utilization of this strategy in the facilitation of critical thinking. Case scenarios enhance active participation by students and encourage creativity, which in itself is crucial in the facilitation of critical thinking (Carlisle \& Ibbotson, 2005).

\section{Purpose of the study}

The specific purpose of this study was to develop, implement and evaluate an educational programme that will promote critical thinking among student nurses in order to empower them to practise critical thinking as professional nurses after completing their studies. However to develop the educational programme a conceptual framework is required as basis for the development of such programme.

\section{Objectives of the study}

The objectives were to develop a conceptual framework for the development of an educational programme to facilitate critical thinking among student nurses in nursing practice.

\section{Methodology}

The purpose of this section is to present the process followed to conceptualize the empirical findings arrived at from the needs assessment (phase 1), which reflected the application of critical thinking skills. The ultimate aim was to develop an educational programme to facilitate critical thinking in nursing practice. Mouton (1998) describes conceptualization as the definition of key concepts in a study with a view to integrating one's research into conceptual frameworks.

The findings revealed six main concepts and their related subconcepts. These concepts included interpretation, analysis, evaluation, inference, explanation and self-regulation. These concepts were inferred from the deduction by the researcher. These concepts were the results of the concept analysis of critical thinking by 46 experts directed by Facione (1990), together with the related dispositions. The conceptual framework for the development of the educational programme is presented by defining the central concepts and thereafter provides an outline of the relationship between these concepts. The conceptualization process consists of concepts synthesis, clarification of concepts, interpretation, analysis, evaluation, inference/conclusion, and explanation, self - regulatory and critical approaches. These processes are described as follow:

\subsection{Concepts synthesis}

Concept synthesis was conducted to cluster the essential concepts, which according to the literature; any nurse should have in order to cope with managing a problem situation in nursing practice. 
An extensive number of 36 concepts were deductively arrived at on the basis of students' answers to questions on an imaginary case scenario. These concepts served as quantitative evidence of the skills that are required from nurses to address and manage a problem case in nursing and were supported by literature on critical thinking. However, because of the number of concepts, it was essential to reduce the number of concepts by concept synthesis. To reduce, by synthesis, is seen as the process of forming an opinion about something on the basis of information or evidence that is available (Hornby, 2005).

In this study the researcher used synthesis to cluster the concepts arrived at, from the analysis of the scenarios, into six meaningful concepts, namely interpretation, analysis, evaluation, inference, explanation and self-regulation applicable to the nurse in Namibia, as illustrated in fig 5.1. The literature supports these concepts as important ones for any critical thinker to possess. These six concepts fit into the framework of Facione (1990) where the 46 respondents participated in a Delphi study, where-after the six core critical thinking concepts were renowned. These six concepts were also used to formulate the pedagogical tools for the educational programme as.

Although critical thinking entails much more than the six main identified concepts, the researcher is of the opinion that the nurses in Namibia should master these concepts in order to manage a patient/client case in health care with a critical approach, and thereby find the best solution to the problem. The researcher is also of the opinion that if they could master all or some of these six main concepts, it could result in a remarkable improvement in nursing care in Namibia.

Although many definitions and concepts of critical thinking are described and explained in the literature, many nurse researchers internationally have attempted to use existing frameworks as that of Facione (1990) to develop assessment tools and programmes to facilitate critical thinking. Therefore, synthesis of these concepts into main concepts in this particular study is the result of a logical reasoning process by the researcher. These concepts were considered appropriate for this study because the main six concepts are also indicated in the literature as important skills to have in order to apply critical thinking in nursing practice.

\subsection{Clarification of the concepts}

The main concepts, as reduced by the researcher after the data analysis, described in chapter 4 (phase 1- needs assessment of the study) and illustrated in figs 5.1 and 5.2, are: interpretation, analysis, evaluation, inference, and explanation and self- regulation. The literature also supports these concepts as the most important cognitive skills in critical thinking and the competencies that it is considered each nurse should have in nursing practice (Fonteyn, 1998, p.15).

These concepts will now be defined and clarified in terms of the demarcated area identified for this study, namely nursing practice; they also represent the conceptual framework for the development of the programme. However, supplementary to literature on these concepts and exclusive to this study are the independent traits and skills that the literature considers to be essential to these main critical thinking skills (Facione, 1990) that are required to support the execution of the main concepts, also known as critical thinking dispositions (Facione, 1990). Critical thinking dispositions are attributes or habits of mind integrated into individual beliefs or actions that are conducive to critical thinking (Profetto-McGrath, Hesketh, Lang \& Estabrooks, 2003,). The researcher arrived at these finer subskills by analyzing the data from phase 1 .

Although the researcher realized that critical thinking skills might take a long time to acquire, the objective of this study was to in troduce and sensitize the students to at least these most important critical thinking concepts. It was hoped that this would contribute towards a mind shift in nurses on how to approach a complex nursing problem in a scientific way. Although the concepts will be described separately, it is essential to mention that the concepts are intertwined and not applied independently, as indicated in fig 2 .

\subsubsection{Interpretation of the concepts}

Interpretation is defined as the particular way something is understood or explained. The explanation may take various forms (Hornby, 2005) as dictated by the particular situation. Interpretation is, however, not a concept that is applied in isolation; it includes the ability to understand and explain the meaning of information or an event. In the context of this study this would refer to situations in nursing practice that need to be explained and understood to make a nursing diagnosis (Potter \& Perry, 1999; Feldmand, 2002). The term also refers to comprehending and expressing the meaning and significance (Fonteyn, 1998) of data and actions in nursing practice, which includes observations made by utilizing one's senses. Examples of observation refer to the following: seeing wound drainage and smelling whether the drainage is offensive or not, hearing the tone of a patient's voice in a conversation and feeling the dryness of a dehydrated patient's skin. All these observations will assist the nurse to plan nursing care by interpretation since nothing in clinical practice happens by chance (Meyer, Naude \& van Niekerk, 2004)

Interpretation in nursing practice is furthermore essential when nurses have to make vital decisions regarding patient care in the course of their daily duties by interpreting information they have collected about a patient (Kozier et. al., 2004). The ability to understand and comprehend the meaning of the data is equally essential (Longacre, n.d.). Critical thinkers do not jump to conclusions. Instead they ensure that they are well informed and have all the information they need to proceed to an interpretation (Botes, 2000). Nurses of the new millennium need to do more than merely perform tasks; they have to think clearly about what they are doing and what the results of their actions will be (Meyer, Naude \& van Niekerk, 2004).

To be able to interpret any data, the nurse has to show perseverance in seeking for as much information as possible on the patient before an interpretation can be made (Kozier et. al., 2004). In their search for data to interpret it is necessary that the nurse should also display an inquiring mind by asking 'why?' questions to obtain as much information as possible about the situation. They should display curiosity in searching for more information in order to learn as much as possible about the situation in order to facilitate the planning of the nursing care of a particular client/ patient. A nurse should never be satisfied with the minimum of information, but should ask challenging questions to solve complex health care problems. Hence, interpretation also refers to accurately interpreting problems as well as subjective and objective data from common sources on the care of the patient (Simpson \& Courtney, 2002: ADEA, 2006).

Curiosity, inquisitiveness and showing an inquiring mind are three essential concepts related to interpretation as a central concept to critical thinking. Inquisitiveness is considered a measure of intellectual curiosity and desire to learn. It is described as "one's intellectual curiosity and one's desire for learning even when the application of the knowledge is not readily apparent" (Conger \& Mezza, 1996, p.11; Hawke, 2004, p.5). To be inquisitive means to have a strong desire to know about something, and it is "the activity to ask somebody questions, showing that you need information or that you have doubts" (Hornby, 2005, p. 359; p. 1190). It is the commitment to learning as much as you can about a topic. It is about asking "why?", "why not?" and "how?" to obtain the necessary information about the patient to make a final interpretation (Facione, Facione \& Giancarlo, 1994, p. 346; Hammond, 2004, p.13).

Asking "why?" questions is valuable in clarifying the meaning of a scenario. It means seeking new information to broaden one's understanding and support curiosity and eagerness to acquire knowledge and learn the reasons for a patient's condition (Alfaro Le-Fevre, 2002; Alfaro-Le Fevre, 2004; Alfaro-Le Fevre, 2004(b)). Questions such as "Upon what do I base my interpretation?" might save valuable time in the long run (Robinson, 1998, p.7; Cowley, 2004) to speed up an interpretation. Interpretation with the necessary knowledge is essential for the nurse because 
without this ability the nurse in nursing practice would not be able to explain an event or phenomenon. Good interpretation is the foundation for the identification of a problem in nursing care (Sternberg \& Spear-Swerling, 1996; Lipe \& Beasley, 2004).

What kind of questions are nurses supposed to ask?

In nursing practice especially it is imperative for a nurse to be curious and ask questions about the client/patient, to enable them to plan the best care for the patient by interpreting each patient's scenario. A habit of inquisitiveness is an important precursor of critical thinking, which helps the nurse to search for information until it is possible to make the best interpretation about the patient's case in order to plan the best care for the patient. Asking vital questions is one aspect that is imperative for any critical thinker (Kozier et.al., 2004; Howard College, 2006,).

For successful interpretation it is important for the nurse to tune in to the client's problems as they unfold. Also embedded in searching for information is recognizing the pieces of information or data that are missing and persistently looking for those pieces to enable the nurse to work out an individual nursing care plan. It is imperative that nurses cultivate the "why?" mentality so that they can find out as much as necessary. Facione and others agree that nurses should have the internal motivation to be inquisitive about real problems at hand in order to arrive at the best solution (Facione et. al., 1997(a), p.70; Fonteyn, 1998). Cronin \& Rawlings-Anderson (2004) argue that adopting a questioning approach and looking for a range of solutions to nursing problems go hand in hand with the development of critical thinking skills in nursing and are important in proper interpretation.

Hence, for the nurse to reach a proper interpretation of the information at hand, they need to exercise intellectual empathy (Paul, 1990) to imagine how the patient might feel in his situation. Intellectual empathy corresponds with the general meaning of empathy, which refers to understanding another person's feelings, experience etcetera, especially because you have been in a similar situation (Hornby, 2005). Intellectual empathy necessitates imagining yourself in the place of another in order to fully understand that "other" to interpret the scenario in question. It is a conscious effort to understand others by putting your own feelings aside and imagining yourself in their place (Alfaro-LeFevre, 1999; Green, 2000). This is an extremely valuable skill to have as it will enable the nurse to understand and interpret what a patient is going through or why a patient decides to act or behave in a certain way. Intellectual empathy can be developed by answering appropriate questions, for example:

- Imagine yourself having a life-threatening condition such as AIDS with nurses avoiding your room and then ask yourself the question: How does it feel?

- You have pain and no one responds to your call: What are you thinking?

- You are waiting for the public health nurse who should visit on a Tuesday but it is already Wednesday. How do you feel about that?

Nurses with the skill of intellectual empathy are able to care for patients displaying certain behaviours, because they try to understand the behaviour.

As already discussed, nurses have to interpret a scenario as presented by each patient to enable them to plan the nursing care of the particular patient. It would be impossible for any nurse to interpret their observations without the basic support of background knowledge from which the nurse can recall known facts that sometimes serve as the foundations for further thinking. Total recall means remembering facts or remembering where to find them to assist in the solving of a nursing problem, founded on interpretation of data. Basic support does not only refer to background knowledge, however. It can also include information from others, observation and previously drawn conclusions (McKown, 1997; Rubenfeld \& Scheffer, 1999).

In critical thinking a person should have background knowledge and experience in order to make a credible statement. It does not necessarily mean that the person is right but it puts the individual in a position to make accurate statements (Ennis, 1996).
If for example you do not know what the normal range for blood pressure is (support knowledge), how would you start thinking about the reading of a patient whose reading is way above the "expected normal" (interpretation) (Green, 2000; Alfaro-LeFevre, 2002). With basic support it is possible for the nurse to make judgments and try to clarify a patient's condition. When a nurse uses background knowledge and known facts about all aspects of care, their basic support component of critical thinking is used.

What implication does this have for the nurse? Nurses should be updated with new developments and if it so happens that a nurse ends up in a situation where they need to update their knowledge, they need to do so to be in line with this concept of critical thinking. An easy way of finding out if one has sufficient knowledge is to ask the question: Upon what facts do I base my interpretation and conclusions? To answer that, one would make use of known facts and background knowledge; facts which are considered truths (Green, 2000).

With reference to background knowledge or basic support, Norris strongly (1985) supports this concept by saying that critical thinking cannot occur in a vacuum; it requires individuals to apply what they know about the subject matter (nursing) as well as their common sense and experience. Nurses cannot expect themselves to think critically if they do not have a broad theoretical and experimental knowledge base. Thinking critically in the clinical setting requires the nurse to have experience in the clinical setting. Until nurses have good technical skills such as the ability to put up intravenous infusions, most of their brainpower goes into that and little energy is left to practice critical thinking. Therefore novice nurses need a lot of experience before they are likely to think critically (Brannon \& Carson, 2003, Alfaro-LeFevre, 20045).

Nurses are being encouraged to underpin their clinical decision making on an interpretation made, on the basis of the best evidence and knowledge. Outdated knowledge has no place in modern health care and should be updated continuously (Cronin \& Rawlings-Anderson, 2004,).

\subsubsection{Analysis of the concepts}

Analysis is a way of thinking to which one has to be accustomed (Du Toit, 1995, p.83). It is furthermore a mental process by which one seeks to gain a better understanding of the nature of something by carefully separating the whole into smaller parts. It is also considered to be one of the most important techniques to master in critical thinking. A good example of analysis in nursing is covering all body systems during a physical examination, to get as much information as possible on the patient (Smith-Stoner, 1999, Cowley, 2004; Alfaro-LeFevre, 2004). Analysis, according to Fonteyn (1998), implies identifying inferential relationships among concepts, examining ideas and detecting and analyzing arguments. It requires nurses to think for themselves and consider a wide range of ideas, learn from them and then be able, through analysis, to attempt to form or evaluate judgments on the basis of available/relevant considerations (Jones, 2001; Kozier et. al., 2004).

Nurses are practicing analysis when they investigate a course of action based on objective and subjective data. The analysis of assessment data guides the nurse in determining which problems they can treat independently and which need collaboration or referral (Lipe \& Beasley, 2004, p. 10).

To analyze also means to "closely study or evaluate data" (Green, 2000) and to use reason and evidence to resolve problems in order to put the information in a framework. The Center for Critical Thinking (CCT) defines analysis as the process of making a detailed examination to look into the nature, issue or situation of something (CCT, n.d., p.2). Therefore, analytical thinking is described as "using a logical method of thinking about something in order to understand it, especially by looking at all parts separately; it also means to use scientific analysis in order to find out about something" (Conger \& Mezza, 1996 Pollard, 2002, ; AlfaroLeFevre, 2004(b), p. 9; Hornby, 2005 ). 
All the above-mentioned definitions fit the nursing scenario perfectly and clearly emphasize that nursing cannot do without a person with an analytical mind who can closely explore data in order to make a decision. A nurse who is able to analyze has an analytical approach in nursing her patients while remaining alert to problematic situations (Hawke, 2004). The ability to sift or analyze evidence or arguments and respond flexibly to them is therefore by implication considered a prerequisite to competent and reflective practice. Students should think about the meaning of their analysis and evaluation as it relates to some present and future action in the care of the patient (Facione, Facione \& Giancarlo, 1994; Greenwood, 2000; Varner \& Peck, 2003).

In the process of analysis the student nurse and other categories of nurses should be clear and precise in identifying the factors and should be able to explain why something is a risk factor. However, analysis involves more. It involves focusing on results, considering how much time it will take and drawing conclusions about what you have analyzed. Critical thinkers are people who know how to make crucial judgments in nursing. Professional nurses who can think critically are able to reflect beyond the obvious and analyze and compare ideas to render the best possible care to the patient. These professional nurses possess intellectual autonomy, in that they refuse to accept conclusions without evaluating the evidence (facts and reasons) for themselves. The analytical process also refers to demanding the application of reason and evidence, being alert to problematic situations and inclined to anticipate consequences (Facione, 1998, p.4; Alfaro-Le Fevre, 1999; Green, 2000, p.7; Lipe \& Beasley, 2004, p.5; Alfaro-LeFevre, 2004, p.4).

In order to be alert to complicated situations, the nurse should have the analytical skills needed to organize data into meaningful patterns to help in making a diagnosis. To make a nursing diagnosis, the nurse needs to have the ability to analyze all the information gathered during the assessment and make judgments as to what data are relevant and not relevant to the health problem (Cronin and Rawlings-Anderson, 2004, p.120).

Why is analysis so important to the nurse? Analysis will facilitate the making of choices and decisions in the daily planning of nursing care. Decision making is a very complex process in the everyday life of a nurse. Many decisions have to be made daily about problems and the interventions required to solve those problems in everyday life as well as in nursing. Making choices or decisions is defined as selecting from a number of possible alternatives while caring for patients through the process of analysis, which is not easy because patients frequently have multiple problems and there are multiple signs and symptoms to interpret (Ellis, 1997, p. 325; Brannon \& Carson, 2003, p. 290).

Choices need to be made about the following: nursing interventions, actions, treatments and test data. These choices depict a whole range of independent choices that do not require the supervision or direction of others but do rely on the analytical skills of the nurse. Clinical decision making is all about taking the best action in order to produce the desired goal (Makathini, 1992, p.25 Wilkinson, 1996, p.10; Fonteyn, 1998, p.74). Bandman and Bandman (1988, p. 6) state that critical thinking in nursing consists in sharpening the distinctions between certainty, near certainty and degrees of uncertainty. A nurse learns to discriminate by analysis and by understanding and observing criteria before making any decisions.

Divergent thinking is one of the most prevalent cognitive components of critical thinking and refers to the ability of an individual to analyze a diversity of arguments and opinions (Green, 2000, p.7). This term should therefore be considered along with the clarification of the term "analyzing", which has already been described and discussed as an important skill of critical thinking.

For a nurse divergent thinking is a valuable skill to have because nurses get to know so much about a patient that they will have irrelevant and relevant data to choose from when planning their nursing care for the patient. By screening out all irrelevant data, it is possible to draw accurate conclusions. The skill of divergent thinking can be developed through activities such as distinguish- ing relevant from irrelevant data, drawing accurate inferences, analyzing arguments and recognizing the strengths or limitations of opposing viewpoints. It is also essential that the nurse set priorities for herself in the plan of care for the patient. The orderly planning of care can only be done once the nurse first knows what they want to achieve (Applegate, 1998, p. 202; Green, 2000, p.7; Lipe \& Beasley, 2004, p.65).

Separating irrelevant from relevant data is important in nursing care. Relevant data is usually referred to as the abnormal information about a client/patient which is essential to know, whereas irrelevant data is nice to know but it will not alter the patient's condition and it might not be applicable to the situation on hand.

A nurse can enhance divergent thinking, and thus analysis or breaking down information, by asking themselves the following questions: Of the data I have in front of me,

- Which are most relevant to the care of my patient?

- How would I know if this drug is effective? Or ineffective?

- How will the care for the patient with this condition?

- What can be inferred about this group of data? (Lipe \& Beasley 2004, p.65).

\subsubsection{Evaluation of the concepts}

Evaluation may be referred to as judging the value or forming an opinion about the worth, usefulness or importance of something and it is considered to be an important component of sound critical thinking. The process of evaluation is the assessment of the information obtained - to ascertain its probable trustworthiness as well as its relevance to the particular patient care situation. The nurse has to rate the source of the information for reliability and decide whether the information they obtained is credible, relevant to the current problem and without any bias. Evaluation requires discriminating between ideas and making decisions based on logic and evidence, and the nurse should therefore apply this concept to determine whether the desired outcome was achieved (CCT, n.d., p.8; Kajs, 2002, p.3; Lipe \& Beasley, 2004, p. 10). Evaluation is therefore an ongoing process during the care of a client/ patient, its object being to determine whether what you are doing is in line with the desired outcome.

When the term evaluation is applied to nursing practice, it implies judging the value of assessment findings, treatments and test data. The ability to judge value is an important thinking strategy that will allow the nurse to develop, refine and improve on their actions in the execution of nursing care. Evaluation takes place in nursing practice in the course of all the activities in the nursing care of a patient. Findings that result from interpretation can be judged for the purpose of planning the patient's care according to their needs. Treatment can be evaluated in terms of significance, usefulness, appropriateness and cost. Judging the value of any action can determine the existence and elimination of risk. Evaluation is an ongoing process for nurses throughout their care provision and nurses should be sure of what they evaluate and what they would like quality care for the client/patient (CCT, n.d., p.8; Fonteyn, 1998, p.82).

In order to secure quality in their care, nurses need to be constantly evaluating and correcting their thinking, asking questions like:"What am I missing?", "Do I Know what I need to know?", "What else could be going on here?" and "How can I do this better?" In following this process of evaluating one soon realizes that critical thinking is not "rapid-fire thinking" (Alfaro-LeFevre, 2004(a), p.1)

Evaluation can hardly be done without interpretation, a term which has already been discussed. The latter is defined as "to comprehend and express the meaning or significance of a wide variety of experiences, situations, data, judgments, beliefs or criteria" (Facione, 1998, p.4). Interpretation therefore precedes the process of evaluation. To evaluate her interpretation findings the nurse should employ intellectual integrity and intellectual courage (Paul, 1990, p.6).Intellectual integrity implies holding one's own evidence to the same standard of proof to which one holds that of 
others and being consistent in the standards one applies. This will manifest in questions like:

- Are my assumptions about this patient correct?

- Are my conclusions accurate?

- Am I using the same approach and criteria as I would have used for something I believe in? (Green, 2000, p.5).

This term also includes the evaluation of own thinking to determine whether one has been doing right and willingness to admit when one's thinking may be flawed (Alfaro-LeFevre, 1999, p.10; Alfaro-Le Fevre, 2004, p.4).

Intellectual courage (Paul, 1990, p.6) refers to willingness to listen and "fairly evaluate ideas, viewpoints and beliefs of others" (Zalon, 1998, p.4; Green, 2000, p. 4) even though one may not agree with these ideas or beliefs. It is the awareness of the need to face and fairly address ideas, beliefs or viewpoints to which one has not given serious hearing and the willingness to admit error or change beliefs, known as intellectual humility (Paul, 1990, p.6; Alfaro-LeFevre, 2004(b), p.10; Alfaro-LeFevre, 2004, p.4; Carroll, 2007, p.4).

Both these concepts are important in nursing care because it is important for any nurse to listen to what the patient and his family have to say even if the nurses have a strong aversion or dislike towards what the patient is doing ( e.g a patient with tuberculosis who keeps on smoking).

During the process of evaluation the nurse must be able to reflect on her interpretation and analysis. Reflection has been accepted as the vehicle for professional development within the sphere of nursing and it is considered an important concept to nurture and develop during the development of critical thinking skills, because reflecting allows the nurse to explore their experience and move into a new understanding of the patient's situation. Reflecting, for the nurse, implies having a dialogue with oneself, thinking and rethinking one's actions to determine whether the best action and/or decisions have been taken, and also integrating theory with experience (Caffarella \& Barnett, 1994, p.38; Varner \& Peck, 2003, p.53; Brown \& Rutter, 2004, p.19; Cronin \& RawlingsAnderson, 2004, p.164).

Burnard (2005, p 85) is of the opinion that people's memories are generally poor and by reflecting one can compensate for poor memory by making the time to ponder over what has happened.

To ponder, contemplate or deliberate on something implies that the nurse takes the time to collect data, think a matter through in a disciplined manner, and weigh facts and evidence before making a decision regarding a patient's care. The ideal reflective thinker is concerned about the why, the reasons and consequences of something that happened (Wilkinson, 1996, p.28; Green, 2000, p. 8; Van Aswegen, Brink \& Steyn, 2000, p. 124).

\subsubsection{Interference/ conclusion}

Making an inference/decision is a skill that every nurse should develop and is especially important in the execution of nursing care. The word inference is used in the sense of conclusion, "meaning that the conclusion to an argument is the inference" (Lipe \& Beasley, 2004, p.10). It also refers to the step that takes the nurse from the reason(s) to the conclusion (Ennis, 1996, p.6), using all possible reliable sources such as the patient's family to reach those conclusions

As human beings we frequently make inferences. However, the inferences may be erroneous or others may disagree with them (Wright, 2002, p. 77). An inference is defined as something we suspect to be true, based on a logical conclusion after examination of the evidence or available information. It is further the ability to make correct decisions, based on logical reasoning and on the available information. An inference is furthermore defined as a strong or weak, justified or unjustified conclusion based on information (from the patient), assumptions and sound reasoning. The decisions made by inference will depend on using reliable sources. Clients present with a wide range of experiences, behaviours, signs and symptoms, from which the nurse observes the patient to make an inference about the patient's condition (Rubenfeld \&
Scheffer, 1999, p. 49; Potter \& Perry, 1999, p.65; Lipe \& Beasley, 2004, p.10; Alfaro-LeFevre, 2004, p.283

The Centre for Critical Thinking (CCT) (n.d, p.12) considers an inference to be an intellectual act whereby one reaches an opinion. In addition inferences are viewed as judgments made about data; considered as mini conclusions, while the query to evidence is in fact a sub skill to inference (Facione, 1998, p. 5; Rubenfeld \& Scheffer, 1999, p.132).

Fonteyn (1998, p. 650) describes inference as the IF - THEN proposition which is very valuable in nursing practice since much of the thinking nurses do focuses on the identifying of actual and potential problems. The IF - THEN proposition helps the nurse to anticipate which action to take if certain events occur and when there is a change in the client's status. An example of an IF THEN proposition stated to choose a plan of action might be:

"If the bleeding in the intestine and from the stomach are still present by this afternoon, I suggest a Saline infusion be commenced."

An IF - THEN proposition can also be made during other phases of nursing care when some care has to be judged, for example: "If she weighs about $50 \mathrm{~kg}$ that would help me to know that the dose of Pethidine was sufficient". The IF - THEN proposition also assists the nurse in drawing inferences, which as we have said is a related concept in critical thinking. Thinking about one's thinking on a regular basis helps one to gradually become aware of the IF THEN proposition. Green $(2000$, p.8) describes and supports this IF -THEN proposition as integrating past experiences into present decisions (of which examples have already been given) (Schick \& Vaughn, 1999, p. 138; Green 2000, p. 8).

A useful question to ask in order to practise this skill would be: What experiences from my past impact on the care I am delivering to this client/patient today?

Asking specific questions about a case will guide the nurse towards a full description of the situation. These questions would be when, where and who were involved as well as questions that would mainly focus on the feelings and experience of the nurse while dealing with a situation. By asking and answering these reflective questions the nurse will be able to correct herself and look for some missing information where necessary and by doing this, the nurse will understand actions and events better (Forneris, 2004, p. 17).

Once actions and events are better understood, a decision will imply choosing from the different options by priority setting, which forms an essential part of decision making. In situations where considerations must be weighed and alternatives assessed, priority setting and judgment are imperative (Lipe \& Beasley, 2004, p.4; Weinstein, 1995, p.9).

Hammond (2004, p.2) emphasizes that good decisions require good thinking and the two cannot be separated and that whatever the situation requires, it is necessary for any nurse to have gone through a process of thinking in order to make a judgment and reach a conclusion. It is also necessary for the nurse to rely on what they already knows by recalling cognitive knowledge which then serves as basic support in making decisions and judgments and reaching conclusions. A conclusion is defined as the viewpoint, opinion or position taken about an issue (Diestler, 1994, p.6).

An inference/conclusion which is not based on cognitive knowledge might cause the nurse to miss symptoms and this in turn could cost a patient his/her life. Exercising clinical judgment in nursing practice requires cognitive functioning.

Although the responsibility for making clinical decisions may seem frightening to a nursing student, it is part of what makes nursing such a rewarding and challenging profession.

In the clinical context, the nurse who adapts to critical thinking would be expected to draw judiciously on developed nursing knowledge in forming, evaluating or re-evaluating a clinical judgment. At the minimum, to be effective workers (professionals), nurses must be willing and able to reach informed, fair-minded judgments and conclusions in a variety of nursing situations 
(Facione \& Facione, 1996, p.130; Facione, Facione \& Giancarlo, 1997(a), p.67).

Conclusions and judgments are part of all phases of nursing practice. "Most conclusions are like rest stops on a journey; they provide guidance for travel along the nursing path... the conclusions represent the nurses' thinking about the information at hand" (Fonteyn, 1998, p.89). One reason why nurses use the thinking strategy of drawing conclusions in their practice is to arrive at an opinion about their clients' condition or status.

It is, however, necessary to mention that both experience and expertise can affect the way in which nurses make judgments and it is therefore important that nurses develop their critical thinking skills during their practice as nurses.

When reaching a conclusion or drawing an inference, reasoning forms an integral part of the process. Reasoning is very important to the critical thinker, who cannot simply accept things at face value. "To reason is to form judgment about a situation by considering the facts and using your power to think in a logical way" (Hornby, 2005, p.1213). Reasoning furthermore serves a purpose and is an attempt to answer a question or solve a problem (Wright, 2002, p.101).

Reasoning is considered by some authors to be a synonym for critical thinking, but since reasoning is a highly individualized complex activity, it needs more incisive discussion. Reasoning is only possible if one (the nurse) has self-confidence and trusts in her/his ability to reason, guide others and make decisions. Clearly a career involving any form of thoughtful decision making or problem solving, like nursing, is not indicated for people with little confidence in their ability to reason (Facione, Facione \& Giancarlo, 1997, p. 73; Alfaro-LeFevre, 2004(b), p. 4).

Two types of reasoning essential to critical thinking are inductive and deductive reasoning, considered to be the building blocks of critical thinking in making an inference.

Reasoning however cannot be executed haphazardly and is associated with logic.

Logic, described as "a way of thinking or explaining something" (Hornby, 2005, p.869; Green, 2000, p.7) is also part of inductive and deductive reasoning in order to make an inference. It is furthermore considered as a science that consists in the description and evaluation of arguments (Jones, 2001, p. 10). Mouton (1998, p.71) describes drawing an inference as that "logical jump" one makes from a premise to a conclusion. It is necessary for a nurse student to be able to explain a possible risk factor logically as it is important that nursing actions and procedures should follow a logical order.

Using logic helps the nurse to discover whether things make sense and whether the conclusions are founded on evidence (Lipe \& Beasley, 2004, p.6). Lindberg et. al. (1998, p.5) go as far as to say that critical thinking combines logical and creative thinking.

Another interrelated term to inference is focus. Focus is considered to be the product of inference (Ennis, 1996, p.7) and in terms of a definition refers to giving attention to one particular subject, situation or effort or it could imply the "something" or "the thing or person that people are most interested in; the act of paying special attention to something and making people interested in it" (Hornby, 2005, p.574).

When a nurse focuses she/he can be considered to be goal-oriented and purposeful, qualities which are imperative in the nursing care of a patient and in the execution of nursing tasks. "Purposeful" refers to having a useful purpose as well as acting with a clear aim and with determination to reach a goal (Wilkinson, 1996, p.11; Hornby, 2005, p.1180). In support of the above definition Facione (1998, p.3) considers critical thinking to be thinking that has a purpose, designed to prove a point, "interpreting what something means or solving a problem" by using an orderly, diligent and systematic process, especially in the inquiry phase. By keeping focused on one particular patient's problem the nurse may be able to find the best solution (Conger \& Mezza, 1996, p.11; Cowley, 2004, p.115).

In the process of inference, goal-orientation and focus the nurse need to exercise intellectual humility that involves knowing and accepting the limits of his or her own knowledge. When nurses make decisions/inferences they have to apply intellectual humility, where they admit what they do not know and express willingness to seek new information or to rethink the inference they have made on the basis of available information (Kozier et.al., 2004, p.247). It is important that the nurse is aware of her/his shortcomings in the making of inferences.

What sets critical thinkers apart from other thinkers is that when they recognize the limits they seek more information. This implies that a nurse who ends up in a ward or unit where s/he is confronted with unknown scenarios will seek information to inform herself. Humility also involves being sensitive to one's own biases and prejudices, and admitting what one does not know (AlfaroLeFevre, 1999, p.10; Green, 2000, p.4). This concept further implies that one bases every decision on the assumption one has examined and makes sure that one gets enough information from the patient /client to make a decision while remaining aware that personal bias should not influence the decision (Lipe \& Beasley, 2004, p.8).

Intellectual humility is therefore an important concept to keep in mind when caring for patients with chronic illnesses such as AIDS and where patients do not always do what nurses expect them to do, for example stop smoking when the patient is suffering from emphysema. Bias on the part of the nurse will negatively affect the care he/she renders to the patient. Green $(2000$, p.4) is of the opinion that the nurse should ask herself/himself the following questions to develop or foster an attitude of critical thinking, based on inference:

- How do my biases or prejudices affect the outcome of my client's care?

- What is my first impression of the client's situation?

- How will I know when I need more information?

The skill of inference helps nurses to draw conclusions by weighing alternatives to find the best decision for the benefit of the patient .In order to make judgments the nurse also needs to discriminate between relevant and irrelevant data. Discrimination, according to definition, is to recognize that there is a difference between people and things and also refers to terms like "differentiate" and "distinguish" as synonyms (Applegate, 1998, p.203; Hornby, 2005, p.417).

What makes the skill of inference so unique is that the nurse can practise creative thinking while making choices and decisions about a particular patient. Creative thinking is described by Hornby $(2005$, p.345) as "thinking about problems in a new way or thinking of new ideas". This perfectly fits the nursing care scenario.

The literature also describes the use of creativity in terms of responding to one's "gut" feeling or intuition to respond to a patient's problems. Exploring alternative solutions to a patient's problems, finding a new way (improvising) to do a task when not all the equipment is available, finding an alternative way to cut costs without compromising quality and to consider one's "feeling" about a case are ways to implement creativity during nursing care (Green, 2000, p.8). Alfaro-Le Fevre (2002, p.24) refers to creative thinking as looking for better ways to do things by continually examining whether what one is doing is the best way to do something. It is a productive intellectual skill that creates original ideas by establishing relationships between thoughts and concepts. It involves the ability to break up and transfer a concept to new uses (Wilkinson, 1996, p.8).

Creativity in thinking therefore goes beyond textbook ideas. It means coming up with new, useful ideas. The creative thinker says "let's try this new way". Creative thinking includes being open to new ideas or information which might come from different sources. Creativity is at the root of individualized care because it helps the individual to think "outside the box" (Cowley, 2004, p 150 ). With creative thinking it may not be possible to have a logical explanation for the actions and one may not necessarily have specific outcomes in mind (Wilkinson, 1996, p.10; Rubenfeld \& Scheffer, 1999, p.15; Lipe \& Beasley, 2004, p.7; Alfaro-LeFevre, 2004(b), p.8). 
Whenever an action has been taken or an intervention performed, the nurse needs to be able to give a clear explanation, the term to be discussed next.

\subsubsection{Explanation of the concepts}

An explanation is a function by which to clarify obscure meaning or to show how some puzzling occurrence fits in with or follows from preceding events (Jones, 2001, p.15). Providing explanations for interventions is one way that nurses can ensure that they will uphold high professional standards and that proper communication exists between nursing staff. Another way of describing the term explanation is "giving a rationale" or offering a reason for actions, beliefs or remarks; the key aspect on why things happened (Fonteyn, 1998: p.97; Irani, n.d, p.2). After a conclusion has been reached, the critical thinker should be able to explain clearly how she/he got to the conclusion. The nurse should be able to provide a sound rationale for answers/conclusions. Explanations add value to a conclusion and are about the events or influences that preceded a particular conclusion. Explanation is seen as a holistic term which is provided for different actions in the care of the patient Other aspects for which explanations are sought are therapy, tests and nursing interventions (Lipe \& Beasley, 2004, p.10; Irani, n.d, p.2).

Explaining actions and interventions directly relates to logic. It is necessary for a nursing student to be able to explain a possible risk factor logically as it is important that nursing actions and procedures should be in logical order according to priorities based on the needs of the patient. Using logic helps us to discover whether things make sense, fit into the plan of the patient and whether the conclusion can be based on evidence (Lipe \& Beasley, 2004, p. 6 ; Cowley, 2004, p.117).

A clear explanation can be supported by providing reasons for specific actions or conclusions taken in clinical practice. It is further believed that an explanation provides a rationale for a specific choice of treatment or action and it is considered to be one of the cognitive processes inherent in expert nurses' clinical reasoning. An explanation makes something clearer or easier to understand (Fonteyn, 1998, p.92; McKay, 2002, p.29; Hornby, 2005, p.257).

To be clear on actions, clarification by explanation is important. Through clarification important similarities and differences can be noted, assumptions can be identified and terms can be defined (Green, 2000, p.8). To make clarification more effective it is important for the nurse to recognize how assumptions can affect her actions. For example when a mother brings a child for immunization with dirty clothes one can automatically assume that the child is not cared for and neglected or one can simply assume that the child had been at a day care centre and playing all morning before the mother brought him/her for the injection. It may also be necessary to ask questions to find out as much as possible in order to clarify the scenario (Green, 2000: p.8; Alfaro-Le Fevre, 2002, p.24).

It is important that a nurse should be able to explain how she/he arrived at a certain conclusion or judgment (Facione, 1998, p.5). By implication it is therefore expected of nurses that they, in the execution of their nursing tasks, explain, verbally and/or in writing, what they have done and what they intend to do in the nursing care of a particular patient. The nursing milieu does not have room for mistakes and lack of clarity when it comes to the care of a patient. Providing explanations is one way to ensure high professional standards in the care of the patient because, by doing that, through explanation one can tell how conclusions were reached (ATI, 2004, p.1).

Explanation like all other skills requires practice, but "given our human need to communicate, express ourselves and above all argue for our point of view, students are probably more disposed to this critical thinking skill than others" (Irani, n.d, p.4; Mc Kay, 2002, p.118)

\subsubsection{Self - regulation}

Self-regulation is the process where one self-consciously monitors one's own skills and act upon this (Facione, 1998, p.6). In fact, critical thinkers should be "big enough" to admit that they were wrong or missed something in order to correct them self. How one thinks and feels about oneself and how one perceives one's potential ultimately affects success in working life (Cowin, 2001, p.313). Nurses are no exception here.

For critical thinkers, self-regulation implies continuously assessing their own knowledge and acting upon that assessment, which it is important to do within the nursing context. A prerequisite is that nurses should be honest and open minded about their assessment. Open mindedness refers to the active desire to learn to more sides than one and to give facts as they come and pay full attention to alternative possibilities. A nurse may end up in an unfamiliar situation. This calls for introspection and an admission that "I do not know it all". The nurse's own thinking must be monitored for clarity, precision, accuracy and significance as well as its relevance to the patient's case (Paul, 1990, p.4). Selfregulation helps the nurse to believe that one can "learn to learn" to do it better the next time since they are able to become aware of their own thinking processes (Botes, 2000, p.30; Feldman, 2002, p.16; Pollard, 2002, p. 17; Simpson \& Courtney, 2002, p.96; Hammann, 2005, p.23).

In addition to open mindedness, reflection is also required for successful self-regulation. The nurse as an individual should reflect on the process that leads to a conclusion to determine whether they performed the process appropriately, and whether they had all the facts. Reflection at the evaluative level enabled practitioners to monitor their personal and professional performance to enable them to improve on their actions. The process of reflection will change nothing in itself. The process of reflection can only be of extended value if the individual actually does something with the new knowledge gained through this activity. Reflection is necessary for self-evaluation and to make judgments about standards of practice. Nurse can then correct their own thinking process as needed by recognizing errors and correcting them. Self-regulation occurs in response to self-evaluation whereby nurses are considered to be shapers of their own world (Potter \& Perry, 1999, p.66; Teekman, 2000, p.1133; Williams \& Walker, 2003, p. 135; Lipe \& Beasley, 2004, p.10).

As mentioned previously, reflection is considered an important concept to nurture and develop during the development of critical thinking skills and the notion of becoming a reflective practitioner has become an important one. Reflection entails the ability to recognize that critical thinking is a multidimensional, rather than a linear or step-by-step process whereby critical thinkers are free to integrate new ideas or insights at any time or change their opinions when they have new evidence (Burnard, 1995, p.45; Green, 2000 , p. 8; Cronin and Rawlings-Anderson, 2004, p.164). AlfaroLeFevre (2004, p.9) describes this reflection process as "hemming and hawing" about what was done and then correcting or changing actions by self-regulation. Reflecting brings new ideas and stimulates one to other perspectives. Reflection involves distinctive affective processes and necessarily views the past and envisions the future. It furthermore involves thinking about one's learning (Mentkowski \& Associates, 2000, p.186; Jones, 2001, p.135; Pollard, 2002, p. 213).

Self-regulation can be developed by exercising intellectual perseverance (Paul, 1990, p.6.). Intellectual perseverance in critical thinking is similar to other forms of perseverance which is defined as "continue trying to do or achieve something despite difficulties or a number of setbacks" (Hornby, 2005, p.1083). In nursing practice this term refers to the ability to work through difficulties and frustrations for something you believe in and continue to find effective solutions to client-related and other nursing problems. Nurses with this skill know that sometimes there is no easy answer and it might take time, confusion and frustration to find the best answer. Intellectual perseverance also nurtures self-confidence, which is indispensable in nursing practice. The nurse should have 
the confidence to admit that she is not always right and to share knowledge and initiatives with others in nursing practice (Wilkinson, 1996, p. 31: Green, 2000, p.5; Alfaro-LeFevre, 2002, p.24; Dunlap, 2006, p.19).

For the nurse to have and develop the skill of self-regulation, selfawareness must be evident. Self-awareness refers to knowledge and understanding of one's own character in order to know oneself. It also includes identifying feelings within oneself when dealing with certain situations and scenarios. Critical thinkers should become aware of themselves so that they can improve on shortcomings and find their identity within a certain situation (Hornby 2005, p.1325).

In order to improve on shortcomings it is important that the critical thinker in nursing engage in self-assessment. Self-assessment gives rise to that sense of "how can I improve?" (Mentkowski \& Associates, 2000, p.186) and is defined as "the process of judging your own progress or achievements" (Hornby, 2005, p.1325). It requires the critical thinker to be introspective in order to evaluate and correct own thinking. Introspection means being sensitive to one's own limitations in order to identify areas for improvement by exercising self-questioning. Self-questioning is done to determine whether there are gaps to fill as a result of a lack in information. After introspection or reflection, the critical thinker can reformulate opinions and explanations by means of self-regulation and self-correction. It is important that a critical thinker can assess his/her own ability in order to improve on the shortcomings (Teekman, 2000, p.1132; Alfaro-LeFevre, 2002, p.24).

To improve on shortcomings, critical thinkers should constantly re-evaluate themselves in order to apply self-correction. Awareness of one's fallibility is part of being a critical thinker. Nurses must be engaged in analyzing their interpretation of the problem, explaining their analysis of relevant content or evaluating their inferences about the patient's problem and the choices made (Facione \& Facione, 1996, p.131; Youngblood \& Beitz, 2001, p. 39; Jones, 2001, p.4).).

What are the implications of all the above in taking care of a patient? It implies that if a nurse believes in caring for a patient to the best of her ability, no difficulty, set-back or bureaucratic regulations will stop her/him from doing this. If $\mathrm{s} / \mathrm{he}$ is adamant about becoming a critical thinker, everything will go into developing critical thinking skills. This is the skill which a nurse displays who just never gives up!

\subsubsection{Critical approaches}

For the purposes of this research, the term "critical approach" was used to embrace related concepts to critical thinking on the assumption that if nurses possess the skills embodied in the six main concepts of critical thinking, they possess a critical spirit, applicable to this study as a critical approach. A critical approach refers to the style or set of attitudes evident in critical thinking about one's personal and professional conduct (Van Aswegen, Brink \& Steyn, 2000, p.125; Feldman, 2002, p.24; Williams \& Walker, 2003, p.131; Cowley, 2004, p.114). The six concepts were conceptualized throughout this chapter and described in the preceding text.

A critical approach is embodied in a questioning attitude (which was discussed earlier in this chapter) and includes openness to the examination of nursing knowledge, beliefs, attitudes, issues and intuition in the practice of nursing (Leppa, 1997, p.30).

Facione (1998, p.7) clearly states that a critical approach does not refer to a person who is always negative or hypercritical but that it refers to a person who has a probing inquisitiveness, a keenness of mind, a zealous dedication to reason and a hunger or eagerness for reliable information.

\section{Findings}

The results of the conceptualization process were the denotations supported by the connotative meanings of critical thinking con- cepts which were used to develop an educational programme to facilitate critical thinking in student nurses.

\subsection{Clustering the concepts through concepts synthesis}

These concepts were considered appropriate for this study because the main six concepts are also indicated in the literature as important skills to have in order to apply critical thinking in nursing practice.

\subsection{Application of the concepts in nursing context}

As the study concerns nursing practice, the researcher deemed it necessary to indicate the association of these concepts with nursing as illustrated in fig 5.2. 


\section{PHASE 1}

- Acquire knowledge

- Understand

- Explain, reason, ask "why" questions

- Diligent in obtaining information

- Creative, curious, inquisitive

- Intellectual empathy

- Divergent thinking

- Analyze data

- Identify problem/ Decision making

- Prioritizing/Discrimination

- Independent thinking

- Clear, precise ,open-minded

- Self-confidence

- Credibility of information

- Assess desired outcome

- Decide on best option

- Interpretation

- Creativity

- Intellectual integrity

- Inductive and deductive reasoning

- Make decision

- Query evidence

- Set priorities

- Intellectual humility

- Logic

- Provide rationale

- Describe events leading to a conclusion

- Clarification

- Monitor own thinking

- Self-awareness

- Reflection

- Intellectual perseverance

\section{SYNTHESIS}

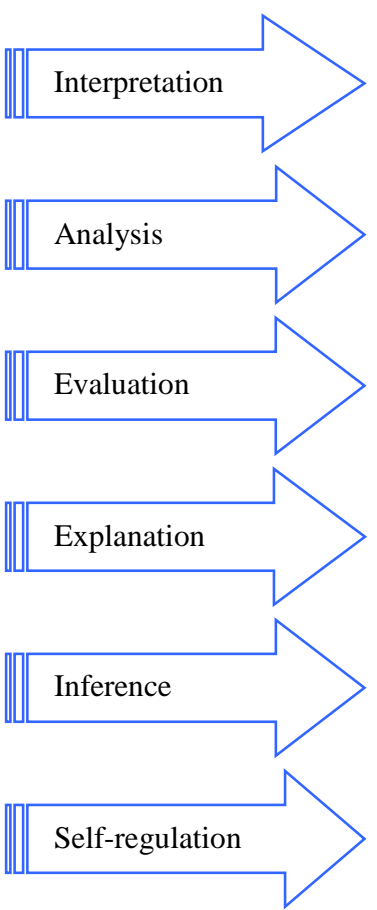

C

Fig. 1: Clustering of Concepts through Concept Synthesis.

\section{NURSING CASE SCE-}

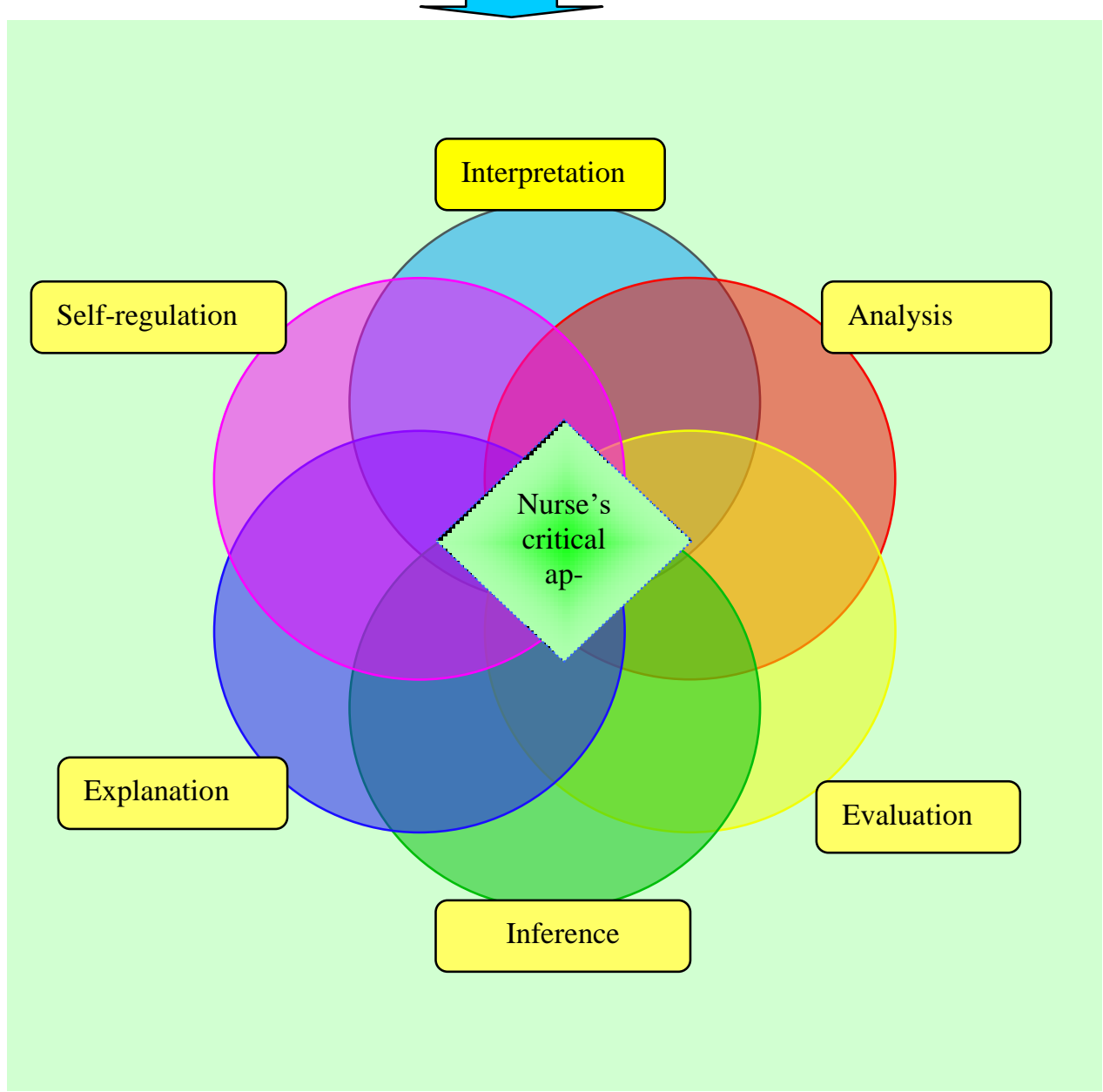

Fig. 2: Schematic Presentation of Critical Thinking Concepts in the Nursing Context. 


\subsection{Relationship between the main critical thinking concepts, sub concepts and critical approaches}

Figure 1 illustrates the relation between critical thinking concepts and sub- concepts in the nursing context.

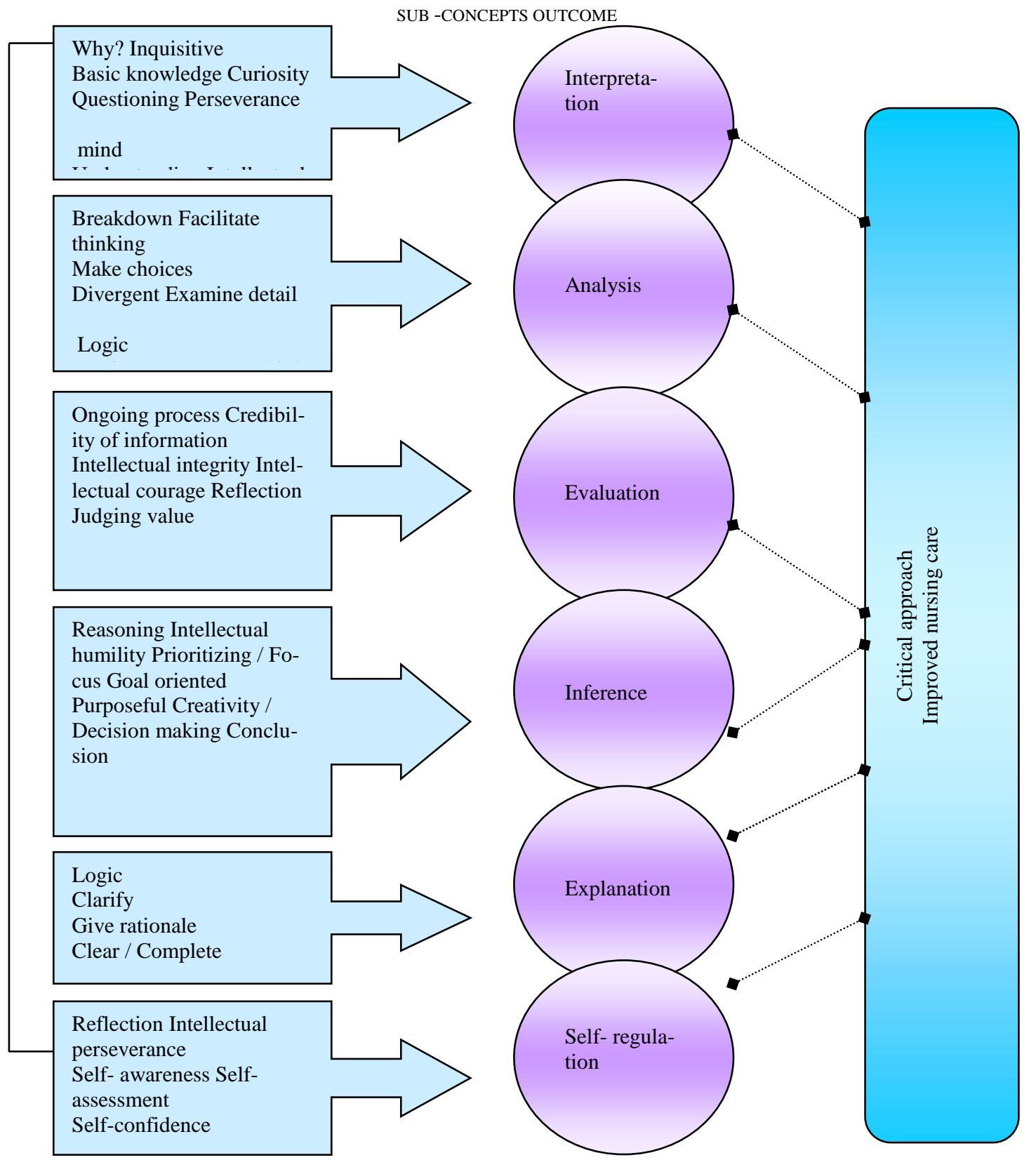

Fig. 3: Graphic Representation of the Relation between the MAIN CRITICAL THINKING CONCEPTS, SUBCONCEPTS AND A CRITICAL APPROACH

\section{Conclusion}

The conceptual framework, in which content of the educational programme to facilitate critical thinking in student nurses was designed and discussed. Six main critical thinking concepts with supportive sub-concepts were identified as essential for any nurse to have and ways to execute these concepts were explored. The facilitation of these concepts was done during the implementation a developed educational programme.

Botes (2000) is of the opinion that the more you practise good thinking, the better you become because it is a matter of "practice it and enjoy it". Critical thinking is not just challenging -- it should also be fun (Smith-Stoner, 1999, p.vi).

Critical thinking requires that one thinks for oneself. Being an independent thinker does not mean ignoring what others think and doing whatever one pleases. Following the ideas of others makes one dependent only if one accepts the ideas without question (Wilkinson, 1996). The development of independent learning means the student becomes able and more willing to take on per- sonal responsibility for learning. Nurses who think critically make high-quality judgments and draw valid conclusions and are thus indispensable to the nursing profession (Profetto-McGrath et. al., 2003).

It was concluded that without an inquiring and insightful workforce, health improvements will not be achieved (Price, 2004) and no changes will be brought about in nursing practice to improve the standards of nursing care.

\section{References}

[1] Mouton, J. (1998). Understanding social research. Pretoria. Van Schaik.

[2] De Vos, A. (2002 a). Intervention research. In A.S. De Vos (Ed.), Research at grass roots: For the social sciences and human service professions (2nd ed., pp.114-126). Pretoria: Van Schaik.

[3] De Vos, A. (2002 b). Scientific theory and professional research. In A.S. De Vos (Ed.), Research at grass roots: For the social sciences and human service professions (2nd ed., pp.28-48). Pretoria: Van Schaik. 
[4] Rubenfeld, G.M., \& Scheffer, B.K. (1999). Critical thinking in nursing: An interactive approach. (2nd ed). Philadelphia: Lippincott, Williams \& Wilkins.

[5] Shin, K.R. (1998). Critical thinking ability and clinical decisionmaking skills among senior nursing students in associate and baccalaureate programmes in Korea. Journal of Advanced Nursing, 27, 414-418. http://dx.doi.org/10.1046/j.1365-2648.1998.00499.x.

[6] Alfaro-Le Fevre, R. (2004 b). Critical thinking and clinical judgment. (3rd ed.). St. Louis, Missouri: Saunders.

[7] Brown, K., \& Rutter, L. (2004). Critical thinking and analysis. A guide to enhancing reflection, learning and writing for post qualifying social work programmes. Dorset: Bournemouth University. Institute of Health and Community Studies

[8] Thurmond, V.A. (2001). The holism in critical thinking: A concep analysis. Journal of Holistic Nursing, 19(4), 375-388 http://dx.doi.org/10.1177/089801010101900406.

[9] Thurmond, V.A. (2001). The holism in critical thinking: A concept analysis. Journal of Holistic Nursing, 19(4), 375-388 http://dx.doi.org/10.1177/089801010101900406.

[10] Simpson, E., \& Courtney, M. (2002). Critical thinking in nursing education: A literature review. International Journal of Nursing Practice, 8(2), 89-98. Retrieved September 13, 2006, from http://eprints.qut.edu.au/archi.PDF. http://dx.doi.org/10.1046/j.1440-172x.2002.00340.x

[11] Salmon, M. (2002). Introduction to logic and critical thinking. (4th ed). Mexico: Thomson Learning.

[12] Brown, K., \& Rutter, L. (2004). Critical thinking and analysis. A guide to enhancing reflection, learning and writing for post qualifying social work programmes. Dorset: Bournemouth University. Institute of Health and Community Studies.

[13] Howard College. (2006). Quality enhancement plan: critical thinking ... for learning, for earning, for life!. Retrieved March 09, 2007 from http://www.howardcollege.edu/QEP/QEP-Plan

[14] Robinson, D.L. (1998). Clinical decision making for nurse practitioners: A case study approach. Washington: Lippincott-Raven.

[15] Potter, P.A., \& Perry, A.G. (1999). Basic nursing. A critical thinking approach. (4th ed). London: Mosby.

[16] Carroll, R.T. (2007). Teaching critical thinking. Paper presented at Critical Thinking Workshop, Las Vegas. Retrieved May 14, 2007, from www.skepdic.com/essays/teachingCT.pdf.

[17] Makathini, J.T. (1992). The problem solving process with specia application to the clinical setting. Curationis, 15(2), 24-26. http://dx.doi.org/10.4102/curationis.v15i2.357.

[18] Mpaka, N.M., \& Uys, L.R. (1999). The critical thinking ability of diplomats from different types of bridging programmes. Curations, 22(3), 14-20.

[19] Buchanan, A. (n.d). Integrating critical thinking into the classroom: Access Excellence @ the National Health Museum. Retrieved August $02, \quad 2006$ from http:// www.accessexcellence.org/LC/TL/buchanan/html.

[20] Facione, P.A. (1990). Critical thinking: A statement of expert consensus for purposes of educational assessment and instruction. Research findings and recommendations. Retrieved November 27 , 2008 , http://eric.ed.gov.ERICWebPortal/custom/portlets/record

[21] Abegglen, J. (1997). Critical thinking in nursing: Classroom tactics that work. Journal of Nursing Education, 36 (10), 452 - 458.

[22] Cooke, M., \& Moyle, K. (2002). Students' evaluation of problem based learning. Nurse Education Today, 22(4), 330 -339. http://dx.doi.org/10.1054/nedt.2001.0713.

[23] Walker, S.E. (2003). Active learning to promote critical thinking. Journal of Athletic Training, 38(3), 263-267.

[24] Alfaro-Le Fevre, R. (2004 b). Critical thinking and clinical judgment. (3rd ed.). St. Louis, Missouri: Saunders.

[25] Hornby, A.S. (2005). Oxford advanced learner's dictionary of current English. (7th ed.). Wehmeier, S. (Ed.). New York: Oxford University Press

[26] Pond, E., Bradshaw, M.J., \& Turner, S. (1991). Teaching strategies for critical thinking. Nurse Education, 16(6), 18-22. http://dx.doi.org/10.1097/00006223-199116060-00007.

[27] Lipe, S. K., \& Beasley, S. (2004). Critical thinking in nursing: A cognitive skills workshop. Philadelphia. Lippincott, Williams \& Wilkins.

[28] Murchù , D. O., \& Muirhead, B. (2005). Insights into promoting critical thinking in online classes. Retrieved November 21, 2006 from http://www.itdl.org/Journal/Jun_05/article01.htm.

[29] Finke, L.M. (1998). Teaching in nursing. In D.M. Billings \& J.A Halstead (Eds.), Teaching in nursing (pp 3-16). Tokyo: Saunders.

[30] Bandman, E. L., \& Bandman, B. (1988). Critical thinking in nursing. Connecticut: Appleton \& Lange.
[31] Walker, L. O., \& Avant, C.A. (2005). Strategies for theory construction in Nursing. (4th Ed.). New Jersey: Pearson-Prentice Hall.

[32] Carlisle, C \& Ibbotson, T. (2005). Introducing problem-based learning into research methods teaching: Student and facilitator evaluation. Nurse Education Today, 25 (7), 527-541. http://dx.doi.org/10.1016/j.nedt.2005.05.005.

[33] Fonteyn, M.E. (1998). Thinking strategies for nursing practice. Philadelphia: Lippincott-Raven.

[34] Profetto-McGrath, J., Hesketh, K.L., Lang, S., \& Estabrooks, C.A. 2003. A study of critical thinking and research utilization among nurses. Western Journal of Nursing Research, 25(3), 322-337. http://dx.doi.org/10.1177/0193945902250421.

[35] Meyer, S.M., Naude, M., \& van Niekerk, S. (2004). The unit manager: A comprehensive guide. Sandton: Heinemann.

[36] Kozier, B., Erb, G., Berman, A., \& Snyder, S.J. (2004). Fundamentals of nursing. Concepts process and practice. (7th ed.). New Jersey. Pearson Education.

[37] Longacre, S. (n.d). Developing critical thinking in the nursing student using simulated online clinical scenario assignments. Retrieved September $14, \quad 2006, \quad$ from http://www.ccone.org/scholars/05 - 06/

[38] ADEA (American Dental Education Association). (2006). Educational strategies associated with development of problem solving, critical thinking and self-directed learning. Journal of Dental Education, 70 (9), 925-936

[39] Conger, M.M., \& Mezza, I. (1996). Fostering critical thinking in nursing students in the clinical setting. Nurse Educator, 21(3), 1115. http://dx.doi.org/10.1097/00006223-199605000-00005.

[40] Hawke, M. (2004). Sim-Lab learning stimulates critical thinking. Nursing Spectrum: Career Fitness Online. Retrieved August 30, 2004, http://community.nursingspec.com/MagazineArticles/article.

[41] Hammond, G.T. (2004). Fit to think: conceptual, critical and creative thinking. Retrieved July 01, 2006 from http://www.au.af.mil/au/awc/awgate/awc - thkg.htm.

[42] Alfaro-Le Fevre, R. (2004). Selfstudy modules: Improving your ability to think critically. Nursing Spectrum:Career fitness [Electronic version]. Retrieved August 06, 2004, from http://nsweb.nursingspectrum.com/ce/ce168.htm.

[43] Alfaro-Le Fevre, R. (2004 b). Critical thinking and clinical judgment. (3rd ed.). St. Louis, Missouri: Saunders

[44] Cowley, S. (2004). Getting the buggers to think. London. MPG Books.

[45] Robinson, D.L. (1998). Clinical decision making for nurse practitioners: A case study approach. Washington: Lippincott-Raven.

[46] Sternberg, R.J., \& Spear-Swerling, L. (1996). Teaching for thinking Washington: American Psychological Association. http://dx.doi.org/10.1037/10212-000.

[47] Lipe, S. K., \& Beasley, S. (2004). Critical thinking in nursing: A cognitive skills workshop. Philadelphia. Lippincott, Williams \& Wilkins

[48] Howard College. (2006). Quality enhancement plan: critical thinking ... for learning, for earning, for life!. Retrieved March 09, 2007, from http://www.howardcollege.edu/QEP/QEP-Plan.

[49] Facione, N.C., Facione, P.A., Giancarlo, C.A.F. (1997 (a)). The motivation to think in working and learning. In E. Jones (Ed.), preparing competent college graduates: Setting new and higher expectations for student learning (pp. 67-79). San Fransisco, CA: JosseyBass.

[50] Fonteyn, M.E. (1998). Thinking strategies for nursing practice Philadelphia: Lippincott-Raven.

[51] Cronin, P., \& Rawlings-Anderson, K. (2004). Knowledge for contemporary nursing practice. Philadelphia: Elsevier Science Limited.

[52] Paul, R. (1990). Critical thinking. What every person needs to survive in a rapidly changing world. Rohnert Park. Center for Critica Thinking and Moral Critique.

[53] McKown, L.K. (1997). Improving leadership through better decision making: fostering critical thinking. A research paper presented to the Research Department Air Command and Staff College Retrieved May 23, 2006, from http://www.au.af.mil/au/awc/awcgate/acsc/97- 0506pdf

[54] Rubenfeld, G.M., \& Scheffer, B.K. (1999). Critical thinking in nursing: An interactive approach. (2nd ed). Philadelphia: Lippincott, Williams \& Wilkins.

[55] Ennis, R.H. (1996). Critical thinking. New Jersey: Prentice Hall.

[56] Green, C. (2000). Critical thinking in nursing. Case studies across the curriculum. New Jersey. Prentice Hall Health.

[57] Norris, S.P. (1985). Synthesis of research on critical thinking. Educational Leadership, 40-45. 
[58] Brannon, L.A., \& Carson, K.L. (2003). Nursing expertise and information structure influence medical decision-making. Applied Nursing Research, 16(4), 287-290. http://dx.doi.org/10.1016/j.apnr.2003.08.004.

[59] Du Toit, P. (1995). Essential thinking skills. Durban. Kagiso.

[60] Smith-Stoner, M. (1999). Critical thinking activities for nursing. Philadelphia. Lippincott.

[61] Lipe, S. K., \& Beasley, S. (2004). Critical thinking in nursing: A cognitive skills workshop. Philadelphia. Lippincott, Williams \& Wilkins.

[62] CCT (Center for Critical Thinking). (n.d). Critical thinking glossary: An educator' guide to critical thinking terms and concepts. Retrieved November 22, 2005, from http://www.criticalthinking.org.

[63] Conger, M.M., \& Mezza, I. (1996). Fostering critical thinking in nursing students in the clinical setting. Nurse Educator, 21(3), 1115. http://dx.doi.org/10.1097/00006223-199605000-00005.

[64] Varner, D., \& Peck, S.R. (2003). Learning from learning journals: The benefits and challenges of using learning journal assignments. Journal of Management Education, 27(1), 23-77. http://dx.doi.org/10.1177/1052562902239248.

[65] Ellis, P.A. (1997). Processes used by nurses to make decisions in the clinical practice setting. Nurse Education Today, 17, 325-332. http://dx.doi.org/10.1016/S0260-6917(97)80064-0.

[66] Brannon, L.A., \& Carson, K.L. (2003). Nursing expertise and information structure influence medical decision-making. Applied Nursing Research, 16(4), 287-290. http://dx.doi.org/10.1016/j.apnr.2003.08.004.

[67] Williams, B \& Walker, L. (2003). Facilitating perception and imagination in generating change through reflective practice groups. Nurse Education Today, 23(2), 131-137. http://dx.doi.org/10.1016/S0260-6917(02)00167-3.

[68] Fonteyn, M.E. (1998). Thinking strategies for nursing practice Philadelphia: Lippincott-Raven.

[69] Bandman, E. L., \& Bandman, B. (1988). Critical thinking in nursing. Connecticut: Appleton \& Lange.

[70] Applegate, M.H. (1998). Curriculum evaluation. In D.M. Billings \& J.A Halstead (Eds.), Teaching in nursing ( pp 179 - 205). Tokyo: Saunders.

[71] Kajs, S. (2002). The imagine project. The Successful Professor, 1(4), 3.

[72] Paul, R. (1990). Critical thinking. What every person needs to survive in a rapidly changing world. Rohnert Park. Center for Critical Thinking and Moral Critique.

[73] Paul, R. \& Nosich, G.M (1991). A proposal for National Assessment of Higher order thinking at the community College and University Levels. [Document reproduced by EDRS]. Washington. National Centre for education Statistics. Retrieved November 24, 2008 from http://eric.ed.gov/ERICDocs/data/ericdocszs9/content-storage

[74] Paul, R. (1995). Critical thinking: How to prepare students for a rapidly changing world. Santa Rosa. Foundation for Critical Thinking

[75] Zalon, M.L. (1998). Political action to enhance critical thinking The Australian Electronic Journal of Nursing Education, 4(1), 1-10.

[76] Carroll, R.T. (2007). Teaching critical thinking. Paper presented at Critical Thinking Workshop, Las Vegas. Retrieved May 14, 2007, from www.skepdic.com/essays/teachingCT.pdf.

[77] Caffarella, R.S., \& Barnett, B.G. (1994). Characteristics of adult learners and foundations of experiential learning. New Directions for Adult and Continuing Education, (62), 29-42. http://dx.doi.org/10.1002/ace.36719946205.

[78] Varner, D., \& Peck, S.R. (2003). Learning from learning journals The benefits and challenges of using learning journal assignments. Journal of Management Education, 27(1), 23-77. http://dx.doi.org/10.1177/1052562902239248.

[79] Brown, K., \& Rutter, L. (2004). Critical thinking and analysis. A guide to enhancing reflection, learning and writing for post qualifying social work programmes. Dorset: Bournemouth University. Institute of Health and Community Studies.

[80] Cronin, P., \& Rawlings-Anderson, K. (2004). Knowledge for contemporary nursing practice. Philadelpia: Elsevier Science Limited.

[81] Van Aswegen, E. J., Brink, \& H.I.L., Steyn, P.J.N. (2000). A model for facilitation of critical reflective practice. Part II - Conceptual analysis within the context of constructing the model. Curationis, 23(4), 123-127. http://dx.doi.org/10.4102/curationis.v23i4.769.

[82] Ennis, R.H. (1996). Critical thinking. New Jersey: Prentice Hall.

[83] Rubenfeld, G.M., \& Scheffer, B.K. (1999). Critical thinking in nursing: An interactive approach. (2nd ed). Philadelphia: Lippincott, Williams \& Wilkins.

[84] Schick, T., \& Vaughn, L. (1999). How to think about weird things: Critical thinking for a new age. (2nd ed). California: Mayfield.
[85] Forneris, S.G. (2004). Exploring the attributes of critical thinking: A conceptual basis. International Journal of Nursing Educational Scholarship 1(1): Art 9. Retrieved January 10, 2006, from http://www.bepress.com/ijnes/vol1/iss1/art9.

[86] Weinstein, M. (1995). Critical thinking: Expanding the paradigm. Retrieved July 01, 2006, from http://www.chss.montclair.edu/inquiry/fall95/weinste.html.

[87] Hammond, G.T. (2004). Fit to think: conceptual, critical and creative thinking. Retrieved July 01, 2006 from http://www.au.af.mil/au/awc/awgate/awc - thkg.htm.

[88] Jones, R.P. (2001). Foundations of critical thinking. Fortworth: Harcourt College Publishers.

[89] ATI (Assessment Technologies Institute); LLC. (2004). Critical thinking. Retrieved June 5, 2005, from http://www.atitesting.com/productinfo/CriticalThinking.aspx.

[90] Irani, T. (n.d). Teaching the critical thinking skill of explanation. $\begin{array}{llll}\text { Retrieved } \quad \text { May 2, from } & \text { 2007, }\end{array}$ http://step.ufl.edu/resources/critical_thinking/explanation.pdf.

[91] McKay, T. (2002). Guidelines for critical thinking: Reasons, explanations and decisions. Mexico: Thomson Learning.

[92] Cowin, L. (2001). Measuring nurses' self-concept. Western Journal of Nursing Research, 23(3), 313-325. http://dx.doi.org/10.1177/01939450122045177.

[93] Botes, A. (2000). Critical thinking by nurses on ethical issues like the termination of pregnancies. Curationis, 23(3), 26-31. http://dx.doi.org/10.4102/curationis.v23i3.686.

[94] Feldmand, D.A. (2002). Critical thinking: strategies for decision making. Menlo Park, California. Washington: Crisp Publications.

[95] Pollard, A. (2002). Reflective teaching: Effective and evidenceinformed professional practice. London: Continuum.

[96] Teekman, B. (2000). Exploring reflective thinking in nursing practice. Journal of Advanced Nursing, 31(5), 1125-1135. http://dx.doi.org/10.1046/j.1365-2648.2000.01424.x.

[97] Williams, B \& Walker, L. (2003). Facilitating perception and imagination in generating change through reflective practice groups. Nurse Education Today, 23(2), 131-137. http://dx.doi.org/10.1016/S0260-6917(02)00167-3.

[98] Mentkowski, M. \& Associates. (2000). learning that lasts: Integrating learning, development, and performance in college and beyond San Francisco: Jossey Bass.

[99] Youngblood, N., \& Beitz, J.M. (2001). Developing critical thinking with active learning strategies. Nurse Educator, 26(1), 39-42. http://dx.doi.org/10.1097/00006223-200101000-00016.

[100] Price, A. (2004). Encouraging reflection and critical thinking in practice. Nursing Standard, 18(47), 46-52. http://dx.doi.org/10.7748/ns2004.08.18.47.46.c3664.

[101] Profetto-McGrath, J., Hesketh, K.L., Lang, S., \& Estabrooks, C.A. 2003. A study of critical thinking and research utilization among nurses. Western Journal of Nursing Research, 25(3), 322337. http://dx.doi.org/10.1177/0193945902250421. 